\title{
DESACORDOS MORAIS NA DEMOCRACIA: A DISPUTA ENTRE TRADIÇÃO E PLURALISMO POLÍTICO NUMA DEMOCRACIA AGÔNICA
}

\author{
[MORAL DISAGREEMENTS IN DEMOCRACY: THE DISPUTE BETWEEN TRADITION AND POLITICAL \\ PLURALISM IN AN AGONIC DEMOCRACY]
}

Marcus Vinícius Xavier de Oliveira * Universidade Federal de Rondônia, Brasil

\begin{abstract}
Resumo: Em que consistem os desacordos morais e que papel eles desempenham numa sociedade democrática? Para o presente trabalho, os desacordos morais, em especial, e todos os demais desacordos sociais em geral, são essenciais à conformação e aperfeiçoamento do sistema democrático, mormente quando o desacordo envolve o embate entre moralidade majoritária (leia-se: tradição) e de minorias. Os marcos teóricos adotados foram $\mathrm{o}$ da democracia agônica de Chantal Moufé e o da identidade do sujeito constitucional de Michel Rosenfeld, e no plano normativo o do pluralismo político. Assim, após discorrer-se sobre a correlação entre desacordos morais e democracia pelo referencial da teoria agônica, apresentou-se os principais elementos da doutrina de Michel Rosenfeld. Concluiu-se, após, com a defesa da distinção entre direito e moral e o dever neutralidade dos órgãos que aplicam as normas jurídicas. O método adotado foi o crítico e procedimento o da pesquisa bibliográfica.
\end{abstract}

Palavras-Chave: Pluralismo Político; Desacordos Morais; Democracia; Agonismo.
ABSTRACT: What do moral disagreements consist of and what they means in a democratic society? For the present work, moral disagreements, in particular, and all other social disagreements in general, are essential to the democratic system, especially when the disagreement involves disputes between majority and minority morality. The theoretical frameworks adopted were Chantal Moufé's agonic democracy and Michel Rosenfeld's constitutional subject identity, and on the normative level, political pluralism. Thus, after discussing the correlation between disagreement and democracy in the framework of agonic theory, the main elements of Rosenfeld's doctrine were presented. It was concluded, afterwards, with the defense of the distinction between law and morality and the neutrality duty of the bodies that apply the legal rules. The method adopted was the critical and procedure that of bibliographic research.

Keywords: Political pluralism; Moral Disagreements; Democracy; Agonism

Há moralistas imoralíssimos. Guerra Junqueiro

Moralistas são pessoas que renunciam às alegrias corriqueiras para poder, sem culpa e recriminação, estragar a alegria dos outros.

Bertrand Russel

\footnotetext{
* Doutor em Direito pela Universidade Estadual do Rio de Janeiro, UERJ, com ênfase em direito internacional, direito penal internacional, filosofia do direito e filosofia política. Professor do Curso de Direito na Universidade Federal de Rondônia, UNIR. E-mail: advmarcusvinicius@gmail.com
} 
O moralista é um hipócrita que reprime nos outros o que não reprime em

si.

Contardo Calligaris

\title{
1261 InTROdução
}

T. L. Lopéz Arangurem, em seu livro Ética y Poltica, de 1966, portanto, escrito numa Espanha que ainda não divisava claramente o final da ditadura franquista, afirmou uma verdade político-sociológica inegável, qual seja

La democracia no es un status en el que puede un pueblo cómodamente instalarse. Es una conquista ético-política de cada día, que sólo a través de una autocrítica siempre vigilante puede mantenerse, como decía Kant de la moral en general, una tarea infinita en la que si no se progresa se retrocede, pues incluso lo ya ganado ha de reconquistarse cada día [...] La democracia nunca puede dejar de ser lucha por la democracia [...] antes y más profundamente que un sistema de Gobierno es un sistema de valores que demanda una reeducación político-moral [...] (LOPÉZ ARANGUREM, 1963)

Essa concepção se aproxima muito àquela que se tem identificado como agônica, posto estar incrustada no paradoxo do já-mas-ainda-não, vale dizer, na noção de perfectibilidade da democracia "real" quando cotejada como o modelo "ideal" em que a igual-liberdade e a igual-dignidade sejam asseguradas a todas as pessoas, indistintamente, bem como da fragilidade das conquistas civilizacionais alcançadas ante as ameaças reais e iminentes de retrocesso.

Ao justificar a sua adesão a essa concepção agonística, Chantal Mouffe o faz a partir dos seguintes argumentos:

\begin{abstract}
Alguns teóricos como Hannah Arendt veem o político como um espaço de liberdade e da deliberação pública, enquanto outros o veem como um espaço de poder, conflito e antagonismo. Meu entendimento do "político" claramente pertence à segunda perspectiva, mais precisamente por ser esta a forma como eu distingo o 'político' da 'política': por "político" entendo a dimensão do antagonismo que tomo como constitutiva das sociedades humanas, enquanto que por "política" compreendo um conjunto de práticas e instituições através das quais se cria uma ordem, organizando a coexistência humana no contexto de conflitualidade provido pelo político (MOUFFE, 2005, p. 9. Livre tradução).
\end{abstract}

A distinção proposta por Mouffe entre política e político é indispensável para se chegar ao conceito de democracia enquanto sistema político por estabelecer a sua alteridade fundamental tanto com relação às formas de governo como das instituições estatais responsáveis por sua permanência na facticidade histórica. Se isso não for possível, ocorrerá aquilo que Agamben tem severamente criticado, como seja, a anfibologia que se abate sobre o próprio conceito de democracia, tornando impossível a comunicação e a práxis políticas. Com efeito, conforme Agamben

O termo democracia soa uma nota falsa sempre que surge nos debates atuais por conta de uma ambiguidade preliminar que condena [a] qualquer pessoa que o usa a não se comunicar. Do que falamos quando falamos de democracia? Qual a lógica subjacente? Um observador atento vai logo perceber que, enquanto ouve a palavra, isso pode significar uma de duas coisas diferentes: uma forma de constituir o corpo político (neste caso nós estamos falando sobre direito público) ou uma técnica de governo (neste caso nosso horizonte é a prática administrativa). Para dizer de outro modo, democracia designa tanto a forma pela qual o poder é 
legitimado como a maneira pela qual ele é exercido. Uma vez que é perfeitamente claro que o último significado prevalece no discurso político contemporâneo - a palavra democracia é utilizada na maior parte dos casos para identificar a uma técnica de governo (algo que, per se, não é particularmente reconfortante) -, é fácil verificar porque quem continua a usá-la, de boa-fé, no sentido anterior, pode experienciar certo mal-estar. Estes dois campos da conceituação (o jurídicopolítico e o econômico-gerencial) tem-se sobreposto um ao outro desde o nascimento da política, do pensamento político e da democracia na polis grega ou cidades-estados, o que torna difícil separá-los [....] Quando o mesmo conceito político fundamental pode ser traduzido tanto como "constituição" quanto como "governo", então nos aventuramos para além da ambiguidade e ingressamos no terreno inexpressivo da anfibologia (um termo da gramática e da retórica que significa a indefinição de [um] significado). (AGAMBEN, 2014, pp. 11-12).

Logo, uma concepção agônica de democracia deve pressupor, pelo menos, três níveis de disputas: a) sobre o significado de democracia; b) sobre os critérios de seu funcionamento enquanto sistema político, isto é, a que se presta e como devem operar as instituições, o que envolve, sem qualquer dúvida, discussões sobre os níveis razoáveis do exercício da violência consentida, de enfrentamento das desigualdades sociais e de gênero, de proteção ao meio ambiente a partir da ideia de pacto intergeracional (DE OLIVEIRA, MOREIRA, 2016, pp. 115-132; DE OLIVEIRA, MOREIRA, 2019, pp. 157-172) etc, e c) o conteúdo das normas sociais (não necessariamente jurídicas) no concernente às pretensões e expectativas sobre a vida boa e justa e de igual dignidade, isto é, uma disputa sobre o valor fundante de uma genuína sociedade decente, que deve assegurar a todas as pessoas o viver bem (DWORKIN, 2011 , p. 1). Mas isso somente é possível se a teoria que a busca compreender estiver imbuída daquele fundamento emancipatório que Boaventura de Souza Santos identifica pela díade "conhecimento prudente para uma via decente" SANTOS, 2001, passim).

No presente trabalho, como indicado por seu título, os dois primeiros problemas serão marginais em relação ao terceiro, aqui tratado a partir do conceito de desacordos morais no contexto de uma sociedade plural.

Para aclarar, a concepção de democracia adotada se aproxima àquela de Adam Pzreworski em Crises of democracy, segundo a qual

A democracia está funcionando bem quando [as] instituições políticas estruturam, absorvem e regulam todos os conflitos que possam surgir na sociedade. [As] Eleições - o mecanismo pelo qual uma coletividade decide quem deve governá-la e como - são os mecanismos centrais pelos quais os conflitos são processados nas democracias. No entanto, este mecanismo funciona bem somente quando as apostas não forem muito grandes, se se perder uma eleição não for um desastre e se as forças políticas que foram derrotadas tiverem uma razoável chance de vencer no futuro (PZREWORSKI, 2019, p. 143)

Em síntese, no contexto das democracias agônicas contemporâneas, os princípios da maioria, da proteção das minorias, do pluralismo político e da inviolabilidade dos Direitos Humanos devem estruturar o como dos conflitos morais e políticos, conflitos que não lhe são acidentais, mas essenciais.

Mas o que se deve entender por desacordo moral? E mais importante ainda, qual a expectativa que se deve ter quando o desacordo envolve a relação bastante assimétrica entre maioria e minorias?

Entende-se por desacordo moral a circunstância de que um mesmo fato histórico-social ou comportamento humano in abstrato ou concreto seja objeto de valoração positiva ou negativa, bem como ocorra a defesa, no espaço público (DE OLIVEIRA, MOREIRA, 2018, pp. 34-82), tanto da necessidade de que ele sirva de 
paradigma positivo e, portanto, repetido por outras pessoas, ou mesmo adotado como parâmetro para a criação de políticas públicas, ou negativo, devendo mesmo, em determinadas circunstâncias, ser proibido. Essas valorações - no sentido de julgamento axiológico - têm como parâmetros códigos morais partilhados comunitariamente.

No que toca à abrangência do desacordo, é possível categorizá-lo em relativo e

128 absoluto.

Será relativo quando, inobstante a sua manifestação, for possível a dissolução em favor de uma decisão moralmente legítima para os contendedores, podendo-se aqui se adotar tanto os princípios fundamentais do pensamento habermasiano comunicação, entendimento e consenso sem coerção - ou o da pedagogia freiriana diálogo, capacidade de escuta e veracidade -. Em Habermas, o desacordo assim resolvido redundará em emancipação social; para Paulo Freire, a aprendizagem que produz transformação social (MEDEIROS, 2015, pp. 1214-1230).

Importante observar que tanto em Freire como em Habermas não é possível haver consenso sobre a mentira.

Com efeito, o dever de verdade, para que ocorra a composição do desacordo social, é condição prima facie, e isso é bastante evidente, pois, sendo a mentira um vácuo linguístico destituído de facticidade ou razão ${ }^{1}$, não é apta a produzir consenso duradouro, embora seja usual no campo da disputa pelo poder, como atesta a história. Entretanto, o ônus político e social da mentira torna a vitória idêntica àquela de Pirro, vale dizer, insustentável, demandando de seus agentes não somente o embuste, mas também o autoengano, a desfatualização contínua e o apelo à violência pura e simples como condição de manutenção do poder (ARENDT, 1999, pp. 15-17).

Já o desacordo moral absoluto é aquele em que os fundamentos morais em que os polos se assentam são de tal forma inconciliáveis e opostos que não é possível uma composição que permita a construção de um caminho mediano. A oposição, por ser absoluta, ilide e impede qualquer consenso, ensejando, nesse sentido, uma disputa pela afirmatividade ou negatividade da valoração atribuída a fato ou comportamento, sendo possível que os oponentes defendam o silenciamento do outro, quando não, em situações particularmente graves, a sua eliminação moral e física.

A questão que se procurará responder é que papel deve ser desempenhado pelas instituições democráticas no contexto de desacordos morais, sejam eles relativos ou absolutos.

Os marcos teóricos que darão fundamentação e direção à busca dessa resposta são, no aspecto normativo, o princípio do pluralismo político, e no teórico-dogmático a teoria liberal desenvolvida por Michel Rosenfeld em seu ensaio "A identidade do sujeito constitucional", temas que serão abordados no próximo tópico.

\section{DEMOCRACIA E PLURALISMO: UMA LEITURA A PARTIR DA IDENTIDADE DO SUJEito CONSTITUCiONAL DE MiChEL ROSENFELD}

Michel Rosenfeld é professor titular da Cátedra Justice Sidney L. Robins de Direitos Humanos da Benjamim N. Cardozo Scholl of Law - Yeshiva University, Nova Iorque, sendo sectário do liberalismo político anglo-saxônico que foi defendido por, entre outros, John Rawls e Ronald Dworkin.

Essa linha da filosofia política contemporânea - que está centrada no princípio do pluralismo político - funda-se sobre as exigências político-jurídicas necessárias para a constituição de uma sociedade modelada pela diversidade de opiniões acerca do bem e da vida boa (diversidades ético-morais), o que pressupõe a coexistência de variados grupos que lutam pelo reconhecimento e concretização de seus direitos fundamentais mediante a (re)afirmação de princípios da moralidade política, em especial, o princípio 
da igual dignidade de todos perante o direito, o que ilidiria, absolutamente, discriminações e tratamentos humilhantes a qualquer pessoa ou grupo (TAYLOR, 2018, pp. 34-82).

Em dois momentos distintos de sua obra Rosenfeld afirma a relação indissociável entre o constitucionalismo e o pluralismo:

O constitucionalismo não faz sentido na ausência de qualquer pluralismo. Em uma comunidade completamente homogênea, com um objetivo coletivo único e sem uma concepção de que o indivíduo tem algum direito legítimo ou interesse distinto daqueles da comunidade como um todo, o constitucionalismo [...] seria supérfluo (ROSENLFED, 2003, p. 21, nota 13).

E, “[...] o constitucionalismo depende do pluralismo e pode, em última instância, ser visto como aquele que outorga os meios para institucionalizar o pluralismo". (ROSENLFED, 2003, p. 36).

Para que fique claro, constitucionalismo é sinônimo de democracia constitucional, vale dizer, o sistema democrático regulado por princípios e regras constitucionais e vinculação imediata e inerradável aos Direitos Humanos.

Frente a isso, o autor procura fundamentar a construção da identidade do sujeito constitucional a partir de uma ética pluralista, em que o constituinte, ao fundar um Estado Constitucional, deve renunciar às suas identidades pré-constitucionais e firmar-se sobre o pluralismo como sua característica mais proeminente. Essa construção se dá necessariamente pelo discurso jurídico, mormente o discurso jurisdicional, na medida em que a identidade do sujeito constitucional, por ser evasiva, prenhe de vacuidade, precisa ser reconstruída a cada momento de modo a (re)legitimar a Constituição dentro dos parâmetros do constitucionalismo, donde surge, no entender de Rosenfeld, uma tensão entre Constituição (enquanto texto) e o direito constitucional (princípios político-morais a serem implementados), tendo como paradigma de um governo limitado (check and balances), com respeito aos direitos fundamentais e os princípio da Rule of Law.

Como afirmado, Rosenfeld afirma que a identidade do sujeito constitucional é problematicamente evasiva. Essa já se inicia no próprio conceito de sujeito constitucional, pois o termo, em inglês - constitucional subject - pode denotar três significados distintos: a) subject pode denotar o mesmo que súdito, como seja, aquele que se sujeita à Constituição, b) subject também pode denotar aquele que tem o poder de elaborar a Constituição, como seja, sujeito constituinte, e c) subject, por fim, pode denotar o conteúdo, o componente normativos das normas constitucionais (subject matter).

Além disso, o problema persiste mesmo que se possa estabelecer com precisão o "o quê" e o "quem" significam sujeito constitucional, na medida em que existe uma propensão em ligá-lo, por suas relações, profundas e complexas, com outras identidades relevantes, tais como as identidades nacionais, culturais, étnicas e religiosas. Ademais, a identidade constitucional é propensa a se alterar com o tempo, abarcando ora um significado ora outro, conforme a interpretação que se faça da expressão, devendo-se, portanto, fazer-se a sua reelaboração através de um entrelaçamento entre o passado e o futuro das gerações que se sujeitam à Constituição.

No contexto do problema do entrelaçamento, o autor aponta a complexidade que decorre de uma Constituição escrita na relação que ela tem consigo mesma, vale dizer, a possibilidade de se fazerem interpretações distintas do mesmo texto constitucional. Que fazer? Socorrer-se da concepção originalista (a Constituição significa o que os fundadores da Constituição entendiam que ela deveria significar), ou socorrer-se na necessidade de reinterpretação e reconstrução do texto constitucional a fim de 
compatibilizá-la com a geração presente? Ademais, uma Constituição é necessariamente incompleta, no sentido de que não lhe é possível nem recobrir toda a matéria constitucional relevante, como é certo que ela não o faz, uma vez que a necessidade de regulação constitucional de determinada matéria surge da necessidade político-jurídica historicamente dada, sujeitando-se, por consequência, a distintas interpretações. Assim, uma constituição escrita deve ser necessariamente aberta à interpretação, mesmo que isso pressuponha aceitar-se uma multiplicidade de interpretações divergentes, embora igualmente defensáveis.

Igualmente o problema das emendas à Constituição impõe um caráter evasivo e conflitivo da Constituição consigo mesma, pois, haja uma maior ou menor facilidade para que a Constituição seja emendada, sempre surge o questionamento: estas emendas destoam da identidade constitucional? O caso da Hungria é bastante interessante: com o passar desta nação do socialismo para o capitalismo, a partir de 1989 , somente o dispositivo que prevê Budapeste como capital da República permaneceu. Qual a identidade dessa "nova" Constituição frente àquela originária? (ROSENFELD, 2003, p. 20)

No contexto acima, a própria Constituição Americana é bastante expressiva neste sentido: antes da Guerra da Secessão, permitia-se a escravidão (caso Dread Scott v. Stanford), sendo que com o seu término, a escravidão ela foi proibida (Emenda XIV), permitindo-se, no entanto, a segregação racial (regra separate but equal, caso Plessy v. Ferguson), para, ao depois, se negar a possibilidade da própria segregação (caso Brown v. Board of Education). Que identidade constitucional permaneceu no correr de todas essas alterações?

Pois bem. Segundo Rosenfeld, o constitucionalismo impõe, para a formação da identidade constitucional, um confronto entre pluralismo tradição, que identifica as diversas identidades pré-constitucionais, tais como religião, etnia, cultura e nacionalidade. Esse confronto se concretiza pela imposição de limites às identidades pré-políticas da nação (PREUSS, apud ROSENFELD, 2003, p. 21).

A identidade constitucional, por competir com aquelas identidades préconstitucionais relevantes, não pode ser conceituada como mera oposição a elas, porquanto disso decorreria um conceito tão abstrato que não teria qualquer relevância operativa. A identidade constitucional tem, contemporaneamente, fundamento em razões de moralidade política, tais como os direitos fundamentais, o direito de igualdade (equal protection of Law) e a liberdade de expressão. Contudo, estes fundamentos morais só têm relevância e operatividade num contexto em que as identidades pré-políticas não são excluídas por definitivo, mas conformadas pela Constituição. Assim, o direito de igualdade, por ser um conceito abstrato, somente tem operatividade se da sociedade em concreto se poder aferir que tipo de igualdade necessita: meramente formal (ou de oportunidades) ou a material (distributiva).

Disso decorre que a problemática do sujeito constitucional implica, de um lado, na necessidade de se contrapor frente àquelas identidades pré-políticas (nacionalidade, étnicas, culturais e religiosas), ao mesmo tempo em que ele as deve abarcar, porquanto o interprete constitucional, quando da concretização do texto constitucional, jamais se despirá de quaisquer dessas identidades que formam o seu caráter. Em síntese, se ao se formar a identidade constitucional o constituinte se despisse de qualquer dessas identidades, mesmo assim elas se esgueirariam para dentro através da interpretação feita pelo intérprete nelas formado. Sob esse aspecto particular, como dizia Helmut Coing, referindo famoso brocardo horaciano,

$\mathrm{O}$ direito tem que considerar esta natureza do homem se quiser ser eficiente e evitar vicissitudes inúteis. $\mathrm{O}$ direito tem que ter em conta as condições como em realidade são. Nisso radica sua humanidade. Um direito que descure disso corre o 
perigo de praticamente fracassar, e, em todo caso, provocará o desastre e a desdita. A história conhece muitos exemplos nos quais as exigências das leis foram em sentido contrário aos da natureza, e todas estas leis fracassaram. $\mathrm{O}$ homem não pode, à larga, regulamentar contra a natureza das coisas. A proposição "naturam expellas furca, tamen usque recurret" também vigora no direito (COING, 2020, s/p).

Assim, fica evidente que a identidade do sujeito constitucional é algo sempre complexo, fragmentado, parcial e incompleto, o que se mostra bastante evidente numa Living Constitution, como é o caso da Constituição de 1787, uma vez que ela se tem renovado constantemente, sendo, por isso, a identidade constitucional o produto de um processo dinâmico sempre aberto à maior elaboração e revisão. Neste sentido, Rosenfeld analisa o preâmbulo da $\mathrm{CF} / 1787$, através da conhecida expressão "Nós, o povo...", que num primeiro momento se faz anunciar como o sujeito constitucional desta Constituição:

a) abstratamente: Nós, o Povo... informa que tomam parte da identidade do sujeito constitucional não somente os constituintes que a fizeram, como também todas as pessoas que viviam nos EUA à época; além do que, dessa expressão se infere que todos as pessoas não somente reconhecem a legitimidade do texto, como também, conforme Rousseau, se sujeitam à sua normatividade, por expressar a vontade geral;

b) concretamente: os constituintes de 1787 eram todos homens brancos, anglosaxões, protestantes e proprietários de terras e escravos, que de modo algum representavam a todas as pessoas que se sujeitariam àquela Constituição, pois, por definição, se muito, representavam pouco mais de $25 \%$ da população: $50 \%$ eram mulheres, que estavam excluídas do processo político, e $24 \%$ eram negros, a quem não se reconheciam nem mesmo a condição de seres humanos (conforme, aliás expressou o Juiz da Suprema Corte Presidente Taney no seu voto no caso Dread Scott, decisão judicial que corroborou com a eclosão da guerra civil).

c) historicamente: ao se cotejar o Nós, o Povo... com a cláusula "todos os homens nascem iguais" da Declaração de Independência Americana de 1776, que deveria servir de fundamento para a formação do sujeito constitucional, por ser o documento de libertação face à Colônia, evidencia-se a aporia entre o texto e a realidade, seja pela exclusão das mulheres, seja pela negação da identidade humana aos negros. Disto evidencia-se a dissociação entre os autores e os que se sujeitariam à norma constitucional, já que, no caso dos negros, torna-se bastante evidente a sua exclusão enquanto sujeito de direito.

Assim, segundo Rosenfeld, a identidade do sujeito constitucional deve ser considerada mais como uma ausência, um hiato, um vazio, do que como algo concreto e estabelecido do qual se possa extrair legitimidade para o exercício do poder político, o que possibilita: “a) a sua reconstrução, pois, por ser indispensável, deverá sempre ser reconstruída como condição de legitimidade da Constituição;" e "b) a sua complementação, porquanto, para conseguir aquele fim, deverá ser reconstruído, mas sob a condição de que essa reconstrução, esse preenchimento do hiato não poderá ser definitivo ou completo, como seja, a reconstrução será um continuum, um processo permanente pela busca de legitimidade do texto constitucional."

Em suma: a identidade do sujeito constitucional só é suscetível de determinação parcial mediante um processo de reconstrução orientado no sentido de se alcançar um equilíbrio entre a assimilação e a rejeição das identidades préconstitucionais. Contudo, como se dá a formação da identidade do sujeito constitucional?

O modo pelo qual Rosenfeld identifica o processo de formação da identidade do sujeito constitucional se dá a partir de dois marcos teóricos distintos: o primeiro é 
nas teorias da formação da identidade do sujeito na dialética hegeliana - negação; subsunção; negação da negação -, e nas teorias psicanalíticas de Freud e Lacan; o outro é através da teoria linguística na forma da negação, da metáfora e da metonímia. Pela negação se forma a identidade do sujeito como um si mesmo; pela metáfora, o sujeito se aproxima das demais identidades relevantes a partir da analogia e da similaridade; e pela metonímia, se estabelece a identidade do sujeito constitucional pela contextualização do discurso - que é um processo oposto ao da metáfora.

Pois bem. A formação do eu (sujeito) somente se torna necessária quando ele se confronta com o outro. Sem que o outro seja percebido como um outro eu, não se faz presente qualquer problema acerca do sujeito. No tema referido à identidade do sujeito constitucional, esse eu somente torna-se relevante quando contrastado com o outro eu contido nas identidades pré-constitucionais forjadas pela tradição (nacionalidade, etnia, religião e cultura).

O constitucionalismo moderno, que se origina na contradição entre o pluralismo e a tradição, forma-se necessariamente em contraposição com esta, que é o seu outro. Como consequência, o pluralismo constitucional requer que um grupo que se constitua em um eu coletivo reconheça grupos similarmente posicionados como outros eus, e/ou que cada eu individual trate os demais indivíduos como outros eus. Dessa relação surge a contradição entre o eu do pluralismo (eu interno) e o eu da tradição (outro externo). Assim, seguindo a concepção hegeliana, percebe-se que o confronto entre o eu e o outro deriva da separação entre sujeito e objeto. $\mathrm{O}$ sujeito somente reconhece o outro quando, após perseguir a satisfação de seu desejo por meio de objetos, vê que esta satisfação não é perene, na medida em que é levado, após aquela primeira satisfação, a procurar outros objetos, e assim, sucessivamente, sem jamais se satisfazer. Somente quando ele se volta para outros sujeitos é que seu desejo é satisfeito. Portanto, o desejo do sujeito é que impulsiona o eu a buscar o outro.

Entretanto, a dialética da formação do sujeito em Hegel por si só não leva à reciprocidade entre os sujeitos, como se vê na relação entre o Senhor e o Escravo: o Senhor afirma-se como sujeito quando supera o medo da morte e alcança o estado de um eu reconhecido; já o Escravo, por não superar o medo da morte, se submete ao papel que lhe é imposto por aquele que o reconhece. Assim, abdicando de sua identidade, se submete ao Senhor, que é o outro reconhecido/temido. Contudo, por meio da dialética, os papéis se invertem: o Senhor depende do trabalho do escravo para a satisfação de suas necessidades, e tomando o Escravo, como consequência, consciência de seu labor e habilidade, forma a sua identidade no sentido de ser indispensável ao seu Senhor. Assim, o Senhor se torna dependente do Escravo e o Escravo senhor de seu Senhor. Neste sentido, o modo de formação do sujeito em Hegel se dá por meio da sujeição do eu ao outro.

Já na teoria psicanalítica, o sujeito busca a satisfação de seus desejos nos objetos, mas, como debalde, isto não é perene, ele necessita ajustar o seu comportamento por meio da renúncia. Renunciando aos objetos ele obtém o reconhecimento do outro. A relação, portanto, entre sujeito e objeto se revela numa carência de duas formas: a) como ele necessita de objetos para ser completo, ele é, por si só, incompleto; b) o sujeito, enquanto não é reconhecido pelo outro, é uma carência no sentido de não ter senão a negação de seus objetos. Da separação entre o sujeito e objeto surge a sua consciência de que é carente e incompleto. Para isso ele precisa que o outro o reconheça, para que desse ato possa formar a sua própria identidade, suprindo a sua carência e incompletude.

As teorias de Hegel e Lacan, segundo a qual a identidade do sujeito se forma tão somente pela sua sujeição ao outro, parece não corresponder ao processo de formação do sujeito constitucional, posto que na teoria constitucional moderna, principalmente se 
fundada na concepção revolucionária, lhe é atribuído o poder de criar uma realidade político-jurídica ex nihilo (Preuss), sem qualquer consideração pelas identidades préconstituições que possa vir a suplantar.

Ocorre que, mesmo que fruto de uma revolução, o sujeito constitucional não consegue apagar totalmente as identidades pré-constitucionais, e isto se dá por um dúplice movimento, a saber: com o passar do tempo as novas gerações não se sentem mais presas à herança revolucionária, como também não renunciam àquelas identidades pré-constitucionais pretensamente suplantadas, já que, na facticidade histórica, não existe a possibilidade de formação de algo ex nihilo. Isto quer significar que, não obstante se tente espancar a tradição, ela sempre se esgueira para dentro da identidade constitucional formada a partir da revolução, sendo, portanto, a identidade constitucional condicionada tanto pelo passado que se quer preterir quanto pelo futuro que se pretende construir. Não há como o eu revolucionário descartar definitivamente o outro tradicional, pois do contrário, o eu revolucionário não se forma no sentido do constitucionalismo, que é pluralista, mas torna-se, sim, terror, que é arrivista, fundamentalista e integralista.

Assim, o constitucionalismo funda-se sobre o pluralismo, o que impõe a necessidade de se formar uma identidade que transcenda a identidade tradicional, o que torna a identidade constitucional num vazio, numa ausência que se encontrado entre dois polos: a autocompreensão dos constitucionalistas - fundada na tradição - e na nova sociedade política que se quer constituir, fundada no pluralismo, cujo vértice de equilíbrio é o Rule of Law (Estado de Direito), o governo limitado (separação dos poderes) e a inviolabilidade dos Direitos Humanos.

Como se deu nos EUA: um governo limitado pelo sistema de freios e contrapesos (check and balances system): divisão de poderes - Legislativo, Executivo e Judiciário -, cabendo a este, por construção da Suprema Corte, a competência para afastar a permanência das normas inconstitucionais, bem como um governo limitado pela construção do sistema federativo, estribado na repartição de competências entre o governo central (União) e os governos estaduais (Estados-Membros). A Federação permitiu que os EUA moldassem a identidade do sujeito constitucional mediante a conjunção dos interesses federais e os interesses estaduais, de modo que uma não se sobressaísse sobre as demais.

Se há um vazio como característica proeminente da identidade do sujeito constitucional, isso implica que ela é constantemente objeto de ressignificação por intermédio do discurso constitucional pluralista, o que impõe ao agente do discurso abstrair-se de sua própria identidade e fixar na pluralidade de identidades e concepções de vida boa e justa que, legitimamente, coexistem na sociedade. Isto se dá por meio de um discurso contextualizado, e que toma em conta as restrições normativas e factuais relevantes. Como o discurso é elaborado em dado contexto, e como o texto constitucional é aberto-a-uma-finalidade e sujeito a transformações, é pelo discurso constitucional que o sujeito constitucional é inventado e reinventado. Contextualizar, portanto, é construir a identidade do sujeito constitucional de forma adequada e pertinente a uma determinada época. Assim, na medida em que a identidade do sujeito constitucional está aberta à contextualização, por ser, repita-se, incompleta e vaga, é que a sua construção e reconstrução são decorrentes do discurso constitucional.

Isso pressupõe, em vista do pluralismo, que o agente do discurso não pode personificar-se a si mesmo como sendo o sujeito da identidade constitucional. Assim, nem os constituintes, nem os cidadãos e nem os intérpretes da constituição são propriamente o sujeito constitucional. Este se forma a partir da soma de todos estes sujeitos parciais, sendo que, disso, a autoidentidade do sujeito constitucional deve vincular todas as pessoas que se reúnem sobre o conjunto das normas constitucionais. 
Nesse contexto, a teoria de Dworkin - da construção e reconstrução da interpretação constitucional - se faz necessária, pois somente assim, considerando-se o passado, o presente e o futuro, é que se poderá contextualizar a identidade do sujeito constitucional.

No entender de Rosenfeld, a construção e a reconstrução são dois momentos 134 distintos da investigação da incompleta e sempre em desenvolvimento identidade do sujeito constitucional, na medida em que a interpretação constitucional se pauta pela dualidade, ao menos, de decisões "corretas" acerca do problema concreto. Nesse sentido, relembra o autor a famigerada decisão da Suprema Corte no caso Roe v. Wade, da década de 70, em que o tribunal Órgão decidiu, contramajoritariamente, em favor do direito individual da mulher em abortar até o terceiro mês de gestação - como consectário do direito de privacidade - julgando inconstitucional as leis estaduais que criminalizavam a conduta. Contramajoritariamente porquanto nos EUA a maior parte da população é contrária ao aborto. Essa decisão significou um enorme impacto na formação do sujeito constitucional, na medida em que, até hoje, os legislativos estaduais intentam a revisão da decisão, propugnando pela criminalização do aborto ou criando restrições à sua prática mediante, por exemplo, a proibição de financiamento públicos de ONGs ou entidades sociais que tenham como objetivo prestar assistência às mulheres que queiram abortar.

Nesse caso, muito embora a Constituição não regulamentasse em nenhum dispositivo o aborto, a partir de uma reconstrução do direito de privacidade, outorgouse à mulher o direito de optar pela interrupção da gravidez.

O importante no processo de reconstrução é a justificabilidade da decisão, vale dizer, a razão de se optar por uma determinada interpretação em detrimento de outra, o que permite a tomada de posição a favor ou contra a decisão. De qualquer sorte, qualquer decisão constitucional importante envolve uma modificação do sujeito constitucional. Assim, a função da reconstrução é a de harmonizar o velho e o novo no contexto em que aplicado, de forma a se poder formular uma compreensão do sujeito constitucional.

Rosenfeld, tomando como fundamento à teoria reconstrutiva de Dworkin, dela se afasta no tocante àquilo que ele identifica como uma insuficiência para a fundamentação da contrafactualidade. Com efeito, Dworkin, em primeiro lugar, apõem o primeiro requisito da reconstrução em torno dos princípios de moralidade pública por ele defendidos, e que poderiam ser assim resumidos: o direito de cada pessoa a igual respeito e dignidade; em segundo lugar, e que no entender de Rosenfeld é insuficiente, é o critério da coerência, vale dizer, a conformidade da nova interpretação com o corpus sedimentado das interpretações pretéritas. Esta segunda exigência é, no entender do autor, insuficiente, pois impede o exercício da contrafactualidade, vale dizer, a reconstrução da identidade do sujeito constitucional de modo a renová-lo, adaptando-o à realidade social vigente.

A reconstrução da identidade constitucional no âmbito da hermenêutica constitucional se dá por três institutos da linguística: a negação, a metáfora e a metonímia, e se em dois polos, a saber, a autoidentidade do sujeito constitucional (o que ele é) e o constitucionalismo (aquilo que ele deve ser: entenda-se, plural). A isto ele denomina de discurso contrafactual. Por esta narrativa é que é possível preencher-se o vazio a que está condicionado o sujeito constitucional.

Essa reconstrução está sujeita a dois distintos grupos de intérpretes: a) os que pretendem manter o status quo, para os quais a identidade do sujeito constitucional deve ser formada de modo a compatibilizar o eu constitucional como o eu do constitucionalismo, demonstrando, assim, a identificação de um com o outro, e b) os que pretendem apresentar uma cisão entre $\mathrm{o}$ eu constitucional e $\mathrm{o}$ eu do 
constitucionalismo, cujo discurso contrafactual revela os simulacros do discurso meramente legitimante, evidenciando a contradição entre Constituição (o eu constitucional) e Direito Constitucional (o eu do Constitucionalismo).

Seja em "a" ou "b", o discurso constitucional toma como norte de operação as mesmas técnicas, a saber: a) negação: porque o sujeito constitucional somente emerge a partir da renúncia, isto é daquilo que ele não é, para se afirmar, no processo dialético, naquilo que ele é, isto é, na negação da negação, a b) metáfora, também denominada de condensação, na qual a identidade do sujeito constitucional se forma a partir de um discurso que busca apontar as similaridades com as identidades pré-constitucionais rechaçadas na negação, de modo a não se perder na mera negatividade: ele é símile, se identifica com aquelas identidades, mas de um modo a não assimilá-las completamente, mas sim do modo e nos termos em que ele as regula, e c) metonímia, ou deslocamento, pelo qual o discurso é contextualizado, de modo a situar historicamente o sujeito constitucional, pois de modo contrário ele não teria condições de se concretizar no âmbito da sociedade em que inserido.

O papel da negação na formação do sujeito constitucional é multifacetado, intrincado e complexo, na medida em que envolve, dentre outras coisas, a rejeição, o repúdio, a repressão, a exclusão e a renúncia, na medida em que a formação do sujeito, conforme averba Hegel, se estabelece mediante um processo dialético: negação, subsunção e negação da negação. Na negação, o sujeito primeiramente adquire a sua própria identidade mediante a sua negação, já que ela não é redutível aos objetos de seus desejos. Disso surge, entretanto, uma carência, na medida em que a identidade é afirmada tão-somente como aquilo que ela não é; na subsunção, o sujeito parte para a formação de sua identidade de forma positiva, o que envolve, num primeiro momento, na negação de que seja uma carência, um hiato, um vazio, buscando, desta sorte, afirmar-se a partir das múltiplas identidades concretas que o cercam, alienando-se, desta sorte, a si mesmo, já que ele somente adquire identidade afirmando aquilo que é o outro; por fim, na negação da negação, ele assume ser uma identidade distinta de todas as demais, tendo-as assimilado, tornando-se, portanto, um ser para si mesmo.

$\mathrm{Na}$ formação da identidade constitucional se dá o mesmo. Na primeira etapa, negação, ela se afirma como um ser que é distinto do ser pré-constitucional, formado pelas identidades parciais vindas da tradição ou da revolução, para se afirmar como uma identidade plural, e que, portanto, deve recusar aquelas identidades não-plurais. $\mathrm{Na}$ segunda etapa, a subsunção (em Hegel subsumir tem um duplo significado, a saber, extinguir, fazer cessar, mas também preservar, conservar. $O$ que a subsunção extingue é a imediatidade da identidade do sujeito, não a sua existência, que é mediatizada pela identidade que o subsume), pela qual o sujeito constitucional recorre àquelas mesmas identidades vindas da tradição ou da revolução por ele descartadas no processo da negação. O constitucionalismo, sob pena de tornar a Constituição abstrata e não concretizável na sociedade, deve assimilar aquelas identidades, mas não de modo que seja por elas suplantado, mas sim as suplantando, as subsumindo mediante um duplo processo de extinção de suas imediatidades e da preservação de suas mediatidades, como seja, como instrumentos a serviço deste mesmo constitucionalismo, que por definição, é plural. Isto quer significar, precisamente, que o constitucionalismo convive com as identidades pré-constitucionais de forma bastante clara, como seja, não é anulado por elas, mas as conforma de modo a somente valerem nos termos regulamentados pelo pluralismo.

No entanto, por este processo, o constitucionalismo se aliena, pois somente consegue formar-se enquanto sujeito assimilando as identidades que quer suplantar.

Assim, por exemplo, a identidade religiosa é suplantada pelo constitucionalismo para logo depois ser por ele subsumida, como seja, encartada, reservando-lhe, no 
entanto, o espaço privado, de modo a que as demais religiões recebam a mesma proteção.

Numa terceira e última etapa da formação da identidade do sujeito constitucional, que é a negação da negação, o sujeito enfrenta aquela alienação que o habilita a ser alguém subsumindo as identidades que nega. Por este terceiro estágio da dialética, o sujeito toma consciência que ele é um ser para si mesmo, na medida em que, apesar de ter de assimilar as identidades pré-constitucionais que pretendia descartar, ao assimilá-las não se anulou a si mesmo, mas sim que construiu algo novo.

A identidade que se formou é obra sua, e coerente com as suas pretensões, como seja, assimilando as mais diversas compreensões acerca do bem e do justo, e não somente uma. No dizer de Rosenfeld:

Mas quais dessas concepções de bem deverão ser reincorporadas, e em qual medida, é algo que é determinado pelos critérios normativos impostos pelo pluralismo, tornando claro, assim, que a tolerância do pluralismo das diversas concepções de bem resulta de uma posição ativa e não de uma postura passiva (ROSENFELD, 2003, p. 57)

Ao negar a negação de que não é um sujeito, se não mediante uma alienação face as identidades pré-constitucionais, o sujeito constitucional, fundado no pluralismo, se torna um ser para si mesmo. Ele é Senhor de sua obra, e não coadjuvante.

Como visto, a metáfora é um instrumento essencial para o discurso de autoafirmação do sujeito constitucional, na medida em que busca estabelecer a identidade do constitucionalismo a partir de similaridades e equivalências, deixando de lado as diferenças e dessemelhanças. Assim, na asserção presente na Declaração de Independência de 1776 "todos os homens nascem iguais", o discurso constitucional metafórico deve se prender no estabelecimento de afirmações que afirmem as semelhanças entre os mais diversos seres humanos, independentemente de qualquer outro critério, a não ser a natureza humana, rechaçando-se, assim, as diferenças de cor, de raça, de origem etc. Nos Estados Unidos, na decisão confirmatória do regime de segregação (Plessy v. Ferguson), o Juiz Harlan, em voto vencido, afirmou a famosa regra segunda a qual, a Constituição é cega à cor das pessoas (the Constitution is colorblind). Trata-se, como se vê, de um discurso metafórico, centrado no pluralismo, porque se concentra na identidade comum de brancos e negros - seres humanos -, e não no que os diferencia, a cor. $O$ mesmo se passa no entendimento da dimensão constitucional do princípio da proteção da privacidade e da liberdade de expressão. Em 1965, no caso Griswold v. Connecticut, a Suprema Corte entendeu que casais casados tinham o direito de usarem contraceptivos, sendo vedado aos Estados proibi-los; já em 1972, no caso Eisenstadt v. Baird, aquela Corte entendeu que idêntica proteção se estende aos casais heterossexuais não casados.

Contudo, em 1986, no caso Bowers v. Hardwick, a Corte entendeu, por maioria, que os casais homossexuais não tinham, para fins de proteção do direito de intimidade, dos mesmos direitos que os casais heterossexuais, sendo, portanto, constitucionais as legislações estaduais que proíbem e criminalizam o sexo homossexual consensual entre adultos ${ }^{2}$. No entanto, nos votos dissidentes, os Juízes que se posicionaram favoravelmente à idêntica proteção, afirmaram a existência de similaridade entre homossexuais e heterossexuais no que diz respeito ao ponto de vista do sujeito, isto é, quer hetero quer homossexuais tinham o mesmo interesse em decidir como viveriam suas próprias vidas e, mais estritamente, em decidir como se comportariam em suas associações pessoais e voluntárias com seus companheiros. A intromissão do Estado na vida privada de qualquer um deles - hetero ou homossexuais - era igualmente opressiva (ROSENFELD, 2003, pp. 66-67). 
O último instituto de afirmação da identidade constitucional é a metonímia, que opera de modo diverso da metáfora, ou seja, estabelece um eixo de continuidade, de contextualização da identidade do sujeito constitucional frente às identidades préconstitucionais relevantes. Como a identidade do sujeito constitucional é um hiato, um vazio, ele busca preencher este seu vazio por intermédio de sua contextualização junto àquelas identidades pré-constitucionais, numa síntese entre presente, passado e futuro. Mas o passado é de impossível recordação, e o futuro é incerto, donde o presente ser sempre um vazio que se busca preencher.

Os argumentos jurídicos fundados na metonímia evocam as diferenças mediante a contextualização, repousam sobre relações de proximidade para delinear o quadro que revele o máximo possível de detalhes concretos, sendo, portanto, o discurso metonímico um modo de demonstrar que as argumentações metafóricas ultrapassam o caso paradigmático, não podendo, portanto, se tidas como precedentes. Como já visto, no caso Bowers vs. Hardwick a Suprema Corte alegou, por decisão majoritária, que as relações homossexuais praticadas por pessoas maiores e capazes, por livre consentimento, não se assemelhavam de modo nenhum, para fins de proteção constitucional, aos relacionamentos heterossexuais de pessoas casadas ou solteiras, sendo, portanto, válidas as leis estaduais que criminalizam esta prática, pois, consoante voto de um Juiz daquela Corte, é condenado pelo código ético-moral judaico-cristão, que como se sabe, é parte da identidade pré-constitucional dos EUA. Trata-se, como se observa, de um discurso metonímico, que nega a similaridade entre a união homossexual e a união heterossexual, porquanto aquela é negada como legítima pela identidade religiosa preponderante nos EUA.

Dessa sorte, numa síntese possível, vê-se que a negação, a metáfora e metonímia se conjuminam no sentido de estabelecer a identidade do sujeito constitucional. A negação, é claro, delimita o sujeito constitucional ao fazer a mediação entre identidade e diferença. Mas identidade e diferença só podem adquirir formas determinadas ao se utilizar o trabalho da metáfora e da metonímia. Em outros termos, somente a metáfora e a metonímia revelarão qual identidade - ou mais precisamente, quais identidades - e qual diferença - ou diferenças - devem ser mediatizadas pela negação para a produção de uma reconstrução plausível de um sujeito constitucional adequado.

Assim, negação, metáfora e metonímia se estabelecem como padrões de formação da identidade do sujeito constitucional, tomando como ponto de partida a própria vaguidade do pluralismo. Assim, a negação nega o status quo tradicional; a metáfora amplia o plexo de situações constitucionalmente protegidas por assimilação fecha os olhos para as diferenças, visualizando tão-somente os pontos de convergência -, o que, em certa medida, pode tornar a identidade do sujeito constitucional por demais abstrata e descontextualizada de seu medium social; a metonímia, por fim, estabelece um eixo de contiguidade entre a identidade constitucional e as identidades tradicionais mais relevantes e impregnadas no medium social, como, por exemplo, a identidade religiosa. Por este processo, o discurso constitucional contextualiza o sujeito constitucional perante a própria ótica social.

\section{Desacordos morais e MORALIdAde MAJoritária: o ESTUdo PeW}

Pelo que conseguimos apreender do que acima foi exposto da teoria de Michel Rosenfeld é que, ou o regime democrático se funda e se legitima pela pluralidade de concepções acerca da vida boa e justa, ou não o é, seus institutos político-jurídicos devem objetivar o tornar possível o florescimento e permanência dessas concepções (princípio da proteção das minorias), não podendo, entretanto, deslegitimar ou derrogar 
as identidades pré-constitucionais que forjaram a unidade político-moral da comunidade.

Assim, valores morais, formas de expressão religiosas, estórias e histórias sobre o passado, concepções sobre modos legítimos de arranjos familiares e criação dos filhos etc, quando pertencentes à identidade pré-constitucional são recepcionadas pelo sistema político criado pela constituição e passam a ser interpretados e regrados conforme as normas constitucionais, e não por seus próprios fundamentos de legitimação social, sendo submetidos, constantemente, a um processo de retificação em suas eficácias e legitimidades por intermédio da interpretação constitucional, que deve adequar, seja pela negação, pela metáfora ou pela metonímia, a coexistência em igual dignidade e legitimidade com as demais expressões morais, religiosas, tradicionais etc de minorias, não podendo nem um nem outro arrogar-se legitimidade exclusiva, pois o que vale e deve ser perseguido é a manutenção do pluralismo.

Um exemplo bastante significativo. Na Itália, como em muitos outras nações de maioria católica, os prédios públicos em geral, e os órgãos judiciais em particular, ostentam, em lugar central, o crucifixo. Esse símbolo religioso, em sua forma de expressão católico-romano, que retrata a Jesus crucificado, não representa nem aos demais grupos do cristianismo - reformados, evangélicos, pentecostais etc -, quanto mais as muitas religiões não cristãs, como o budismo, animistas, muçulmanismo etc.

Além disso, muitos interpretam, a partir do conceito abstrato de Estado Laico, que nenhum símbolo religioso deve ser ostentado em prédios públicos, pois isso violaria o muro inseparável que deve haver entre Estado e Igreja.

$\mathrm{O}$ caso italiano foi levado à apreciação do Tribunal Europeu de Direitos Humanos pela cidadã italiana Soile Lautsi, que se queixou que, dando a seus filhos uma educação laica, se viam oprimidos em sala de aula, onde são afixados de forma central crucifixos. Em primeira instância, a Corte julgou procedente o pedido formulado pela reclamante, condenando a Itália a retirar os crucifixos de todas as repartições públicas, bem como indenizá-la em 5.000 Euros. Para a Câmara,

A presença do crucifixo, que é impossível não notar nas salas de aula, poderia facilmente ser interpretada por alunos de todas as idades como um símbolo religioso, o que poderia ocorrer de modo a ser educados em um ambiente escolar que tem a marca de uma determinada religião.

Tudo isso pode ser encorajador para os alunos religiosos, mas irritante para indivíduos que praticam outras religiões, particularmente se eles pertencem a minorias religiosas, ou que são ateus.

O Tribunal de Justiça não é capaz de compreender como a exposição, nas classes de escolas públicas, de um símbolo que possa ser razoavelmente associados com catolicismo, pode servir o pluralismo educativo, que é essencial para a preservação de uma sociedade democrática como foi concebido pelo poder do Convenção Europeia dos Direitos Humanos, um pluralismo que é reconhecido pelo Corte Constitucional da República Italiana (TEDH, 2009).

O Estado italiano recorreu da decisão para a Grand Chamber, que retificou a decisão da Câmara, ao considerar que "Nada prova a possível influência que a exibição de um símbolo religioso nas paredes das salas de aula poderia ter sobre os alunos, portanto, é razoável supor que não tem efeito sobre os jovens cujas crenças estão em formação" (TEDH, 2011).

Outro caso bastante interessante é o das árvores Baobás, que no contexto do constitucionalismo africano, são objetos de proteção constitucional como símbolos de coesão e de unidade dos povos africanos, particularmente porque acreditam que elas 
guardam os espíritos de seus antepassados ${ }^{3}$, ou o fato de o Vidovdan - dia de São Vito -, ser feriado nacional, no qual o kosovares comemoram não somente a lembrança daquele santo, mas também a morte do príncipe Lazar e seu exército pelo exército turco-otomano em 1389 na Batalha do Kosovo, e que teve por efeito a ocupação da região por mais de cinco séculos.

É fato histórico-sociológico, nesse sentido, que há um imbricamento na tradição entre religião, política e cultura, o que forja uma identidade majoritária que torna muito complexo os modos pelos quais se expressam as demais identidades minoritárias.

Um índice dessa complexidade pode ser razoavelmente medido pela autocompreensão dos indivíduos acerca da relação entre moralidade e religiosidade, como foi recentemente feito pelo Pew Research Center sob o título "The Global God Divide", publicado em julho de 2020, em que se objetivou aferir em 34 países a [...] cross-national perceptions of religion, including the connection between belief in God and morality, the role God and prayer play in people's lives and the importance of religion" (Pew Research Center, 2020). Para 45\% dos 38.426 entrevistados, somente pessoas que acreditam em Deus podem ter comportamentos morais. Contudo, dependendo do país a que pertence a pessoa, esta percepção altera significativamente: na Suécia, a ideia é apoiada por 9\% dos entrevistados; na Filipinas, 96\%. O Brasil ficou pari passu com essa última, a Indonésia e a Turquia, nações em que o fator religioso é um dos pontos mais destacados de coesão social. Com efeito, no Brasil, para $84 \%$ dos entrevistados existe uma correlação necessária entre fé e moralidade. Contudo, quando decomposto os números para alguns fatores distintivos - idade, escolaridade e orientação política -, tem-se os seguintes dados: a) para jovens com menos de 30 anos esse índice decai 29 pontos do que entre os maiores de 50 anos, isto é $70 \%$ a $89 \%$. Quando o fator é escolaridade, o índice é 77\% para os mais escolarizados e 91\% para os menos. Se a orientação é "esquerda", o índice é de 74\%; se direita, 92\%.

Seja qual for o critério, portanto, a percepção de correlação religiãomoralidade é sempre superior à maioria absoluta em todos eles.

Esses números poderiam ser explicados por vários critérios, mas podemos adotar dois que tem orientado os estudos comparados. O primeiro é o nível de desenvolvimento social, com baixo nível de analfabetismo e conflito social. Quanto mais uma sociedade é desenvolvida, a religião se torna, eo ipso, em fator menos relevante para a coesão social (INGLEHART, NORRIS, 2011).

O segundo fator é o nível é o índice de distribuição de riquezas. Sabe-se que o Brasil é o segundo país mais desigual nesse índice, atrás do Catar. No Brasil, 1\% da população concentra 28,3\% de toda a riqueza produzida, no Catar, 29\%. O terceiro colocado é o Chile, com 23,7\% (ONU, 2019). Sociedades em que o nível de pobreza é acentuado, as religiões desempenham um papel importantíssimo para coesão, o acolhimento, a identidade e proteção comunitária, uma vez que o Estado, quando comparece, não é na execução de políticas públicas de renda básica, mas de atividades eleitoreiras que tendem a manter o coronelismo e o paternalismo políticos. Em síntese, programas de distribuição de renda básica criam condições de emancipação social, ao contrário das atividades eleitoreiras, que geram uma maior dependência políticoeconômica, inclusive no aspecto moral-religioso.

É bastante óbvio que em um contexto de baixo desenvolvimento humano e de elevado nível de desigualdade social que a moralidade majoritária forjada e mantida pela tradição religiosa tende a ser reforçada e transmitida com maior força no contexto social, criando condições bastante desfavoráveis para formas minoritárias de cultura, valores e comportamentos, sempre interpretados ou pelo aspecto da criminalidade (propensão à criminalização de comportamentos minoritários), da medicalização (o 
surgimento ou manutenção dos "ismos", como no caso, por exemplo, do homossexualismo) ou do rechaço discursivo ou físico do "desvio" moral.

Há quem procure resolver o problema entre moralidades a partir do paradoxo atribuído a José Saramago ${ }^{4}$. Afirmam que ao lhe terem perguntado "Como podem homens sem Deus serem bons?", ele respondeu: "Como podem homens com Deus 140 serem tão maus?". Esse tipo de afirmação forma uma polaridade com aquele índice que identifica a correlação entre crença e moralidade. Para o paradoxo saramaguiano, crença em Deus e perversão moral e ignorância intelectual são, no mínimo, siameses; para a outra polaridade, ateísmo e perversão moral são dados como certos.

Numa democracia agônica estas duas polaridades devem existir pois, conforme afirmado em linhas acima, a polarização e a disputa pelos significados e conteúdos das normas sociais é-lhe essencial, pois é deste embate, dos desacordos morais e políticos, que a democracia se forja em sistema político forte o bastante para suportar os testes mais duros. Ademais, desde que Eco e Martini publicaram aquele fabuloso epistolário "Em que creem os que não creem?" que, pelo menos no campo das ciências sociais e políticas, não se poderia interpor qualquer impedimento ao diálogo e à mútua aceitação entre fidentes e ateus (ECO, MARTINI, 2008).

Assim, que papel as instituições democráticas devem exercer nesse contexto?

\section{Algumas conclusões}

As instituições democráticas têm uma moralidade. No entanto, essa moralidade não lhe é atribuída nem pela maioria, pois do contrário não haveria distinção entre tradição e democracia, nem pela minoria, pois isso equivaleria a uma contradição absoluta, pois, caso ela tivesse essa aptidão, não seria minoria.

A moralidade da democracia é aquela que decorre de sua própria identidade constitucional, forjada pelos institutos do governo limitado, do Estado de Direito e da inviolabilidade dos Direitos Humanos.

Assim, a moralidade democrática é decorrente de uma concepção humana, demasiada humana de justiça, qual seja, aquela inerente (decorrente, portanto) e imanente (no sentido estrito do termo, composto pelos termos latino in e manere, e que desde a concepção spinozana, é aquela realidade que se dá e mostra-se a si mesma sem qualquer vínculo ou dependência a uma causa transcendente) (SPINOZA, 2008, pp. 1315) ao Estado de Direito, ao governo limitado, ao pluralismo político e ao Direito Internacional dos Direitos Humanos, o que pressupõe uma separação entre moralidade privada e direito.

Com efeito, segundo Rodolfo Vásquez, o campo de tensão e batalha própria de toda filosofia do direito é aquele pertinente às relações existentes entre direito e moral, vale dizer, as relações possíveis e influências recíprocas que existam entre estes dois campos, se é que elas existam ou deveriam existir (VÁSQUEZ, 2006, p. 17).

Essa concepção que coarcta a comunicação entre direito e moralidade privada parte da distinção kantiana entre direito e moral, como seja, da distinção entre autonomia - derivada do princípio kantiano da maioridade moral do ter-se "[...] coragem de te servires do teu próprio entendimento" (KANT, 1990, p. 9) e heteronomia, identificada por Kant a partir da expressão "[...] a vontade não se dá a lei a si mesma, mas é sim um impulso estranho que dá a lei" (KANT, 2007, p. 90), em que direito e moral são instâncias independentes vis-à-vis, e que se conformam em círculos não secantes e, portanto, estanques no que concerne a uma influência recíproca.

Entretanto, não se pode negar que entre direito e moral possa existir uma correspondência conteudística entre o que é bom/justo mal/injusto. Assim, o estupro, do ponto de vista da moral, é um mal que se pratica em detrimento da autonomia sexual de 
outrem, sendo que, da perspectiva do direito, se constitui em crime, haja vista a reprovabilidade penal do comportamento, uma vez que a autonomia sexual é um bem jurídico penalmente relevante; a corrupção, pública ou privada, é moralmente reprovável e constitui-se em um mal à coletividade, da mesma forma que, para o direito, a prática de atos de corrupção constituem-se em comportamentos ilícitos que atraem, segundo o caso, sanções de caráter político, administrativo e/ou criminal.

Entretanto, apesar da semelhança na reprovabilidade de tais comportamentos, direito e moral têm respostas diversas desde suas estruturas normativas, posto operarem a partir de códigos binários próprios: a moral a partir da polaridade bom $/ \mathrm{mal}$; o direito desde a polaridade lícito/ilícito. Além disso, a natureza da sanção cominada também é diversa: na moral, ou uma autorreprovação pelo agente ou uma de caráter difuso pelos membros da sociedade; no direito, a sanção é de caráter institucional, na medida em que cabe às instâncias pré-existentes ao comportamento ilícito exercer a persecução necessária para se impor ao agente a sanção jurídica.

Aquelas polaridades têm fundamentos em razões de decidir distintas, não podendo ser nem confundidas nem sobrepostas uma à outra em razão da decantada autonomia vis-à-vis, mormente porque em muitas circunstâncias da vida social aquela correspondência entre preceito moral/prescrição jurídica não existe, como o demonstram alguns temas da vida pública em que existem dissensos morais irredutíveis à conciliação, tais como o aborto, as uniões homoafetivas, a eutanásia, a descriminalização das substâncias estupefacientes, a inserção de temas sensíveis do ponto de vista da moralidade majoritária nos regimes de educação etc. Em tais casos, como dito, ante a impossibilidade de consenso - são dissensos morais profundos -, não cabe ao direito optar por uma concepção moral "A" ou "B", mas permitir, desde o postulado da neutralidade, que as normas jurídicas regulem tais comportamentos a partir dos princípios jurídicos que lhes dão espeque e legitimam a sua vigência jurídiconormativa.

Dois exemplos ajudarão a entender o problema:

A) O conceito majoritário de família tradicional, isto é, patriarcal, formado pelo vínculo matrimonial entre homem e mulher, com o objetivo de apoio mútuo e criação de prole, e que se encontra hoje em franco declínio frente a outras formas de estruturação dos núcleos familiares. Em síntese, ele não corresponde à realidade sociológica atual, salvo, talvez, enquanto capa da cartilha de alfabetização "Caminho Suave" e nas pregações de grupos majoritários. Além disso, não se constitui, em absoluto, no único modelo de família protegido pelo Direito.

Conforme decidiu a Corte Interamericana de Direitos Humanos no Caso Atala Riffo e crianças, de 2012, a proteção do núcleo familiar de intervenções indevidas não contempla nenhum modelo predeterminado pela tradição, uma vez que o Sistema Interamericana de Proteção aos Direitos Humanos não fez opção por nenhum paradigma de arranjo familiar, no caso, hetero ou homoafetivo.

B) O problema do estatuto jurídico do embrião e a cláusula "em geral desde a concepção". O Sistema Interamericana de Proteção aos Direitos Humanos não prevê, expressa ou implicitamente, nenhuma vedação quer à descriminalização do aborto quer a práticas que tenham por finalidade a manipulação de embriões humanos para fins reprodutivos.

A tese defendida pelos campos fundamentalistas ditas "pro vida", que apelam abstratamente para a cláusula "em geral desde a concepção" do artigo 4.1 da Convenção Americana, o fazem ou por ignorância ou por má-fé, ou, pior, pela soma dos anteriores, já que, conforme atesta o processo legislativo de deliberação e aprovação desse Tratado, essa cláusula foi inserida no texto convencional para permitir: 1) que os Estados que já permitiam o aborto aderissem ao texto e 2) que os Estados, segundo suas 
políticas de saúde e de garantia dos direitos da mulher, em particular reprodutivos, adotassem políticas públicas variadas para a regulamentação do aborto, inclusive a sua legalização, mas jamais a sua proibição absoluta (Caso Artavia Murillo e outros, 2012).

Entretanto, é bastante óbvio que uma democracia agônica pressupõe que nas diversas fases de deliberação acerca de um projeto de lei ou política pública os mais

142 diversos argumentos advindos do direito, da moral, de concepções religiosas, econômicas, dentre outras, se expresse, o que tende a esfumar aquela autonomia normativa entre os campos, e desde uma perspectiva democrática e plural, esta esfumação é plenamente legítima, guardados os limites de legitimidade discursiva decorrentes dos princípios da universalidade ${ }^{5}$ e da não-discriminação. Contudo, uma vez promulgada a norma, a autonomia entre direito e moral deve prevalecer sobre as opções morais, políticas, econômicas daquele que irá aplicar a norma.

Assim, não é função das instituições democráticas fazer uma opção entre moralidade majoritária e minoritária, de forma a tomar partido no contexto de dissensos morais, sejam eles relativos ou absolutos.

Os dissensos são, por definição, a substância de uma democracia que pretenda resistir aos ataques mais duros contra as suas instituições, partam estes ataques da maioria ou de minorias.

O que se deve exigir das instituições é neutralidade normativo-institucional na aplicação do ordenamento jurídico, de forma a acolher-se ou rechaçar-se proposições morais, majoritárias ou não se e desde que compatíveis com os seus princípios fundamentais.

O critério, portanto, nunca será a adequação do ato ou do fato à moralidade majoritária, mas a sua conformação e tipicidade democrática, apreendidos não da concepção individual do aplicador - que deve ser, no mínimo, irrelevante, ou se não o for, que ele se declare suspeito para decidir -, mas do próprio arcabouço democrático que tem por finalidade última assegurar a dignidade da pessoa humana, a sua autonomia e a inviolabilidade do indivíduo e a prevalência dos interesses coletivos.

Nesse sentido, e para retomar um dos pontos centrais da teoria de Michel Rosenfeld, determinar historicamente o conteúdo dos direitos humanos não implica em ficar-se preso à tradição ou abraçar-se, sem medida, pretensões morais e políticas que se apresentem como progressistas, mas sim permitir a coexistência agonística num contexto em que o direito e as instituições resolvam os dissensos morais de acordo com os princípios fundamentais de uma sociedade livre, justa e solidária.

\section{REFERÊNCIAS}

AGAMBEN, Giorgio. Nota introdutória sobre o conceito de democracia, in DANNER, Fernando, Danner, Leno Francisco, DAGIOS, Magnus, KONZEN, Paulo Roberto. Democracia, política, representação: ensaios filosóficos, tradução de Marcus Vinícius Xavier de Oliveira, Porto Alegre: Fi, 2014, pp. 11-16.

ARENDT, Hannah. A mentira na política - Considerações sobre os Documentos do Pentágono, in Crises da República, tradução José Wolkmann, São Paulo: Perspectiva, 1999, pp. 9-48.

COING, Helmut. O sentido do Direito, tradução de Marcus Vinícius Xavier de Oliveira, in DE OLIVEIRA, Marcus V X, DANNER, Leno Francisco. Filosofia do Direito e Contemporaneidade, II, São Carlos: De Castro, 2020 [no prelo])

CORTE INTERAMERICANA DE DIREITOS HUMANOS. Caso Artavia Murillo e outros ("Fecundação in vitro") vs. Costa Rica. Sentença de 28 de novembro de 2012, 139 p.

CORTE INTERAMERICANA DE DIREITOS HUMANOS. Caso Atala Riffo e criança vs Chile. 
Sentença de 24 de fevereiro de 2012, 101 p.

DE OLIVEIRA, Marcus Vinícius Xavier, MOREIRA, David Alves. Direito ao desenvolvimento, políticas públicas e os Objetivos de Desenvolvimento Sustentável: uma compreensão desde o princípio da interdependência, in PINTO, Renata, GLASENAPP, Ricardo (Orgs). Propostas para uma nova nação: o futuro do Brasil em perspectiva, Belo Horizonte: D’Plácido, 2019, pp. 157-172.

DE OLIVEIRA, Marcus Vinícius Xavier, MOREIRA, David Alves. Ensaio sobre o conceito de desenvolvimento, in DANNER, Leno Francisco, DANNER, Fernando, DE OLIVEIRA, Marcus Vinícius Xavier (Org.). Direito e/ ao desenvolvimento: ensaios transdisciplinares, Porto Alegre: Fi, 2016, pp. 115-132.

DE OLIVEIRA, Marcus Vinícius Xavier, MOREIRA, David Alves. Sobre o espaço público: conceito, princípios e o pluralismo político, in DE OLIVEIRA, Marcus Vinícius Xavier, DANNER, Leno Francisco, CEI, Vitor et al. (Orgs). Direitos humanos às beiras do abismo: Interlocuções entreDireito, Filosofia e Arte, Vila Velha: Praia Editora, 2018, pp. 34-82.

DWORKIN, Ronald. Justice for Hedghogs, Harvard: Harvard University Press, 2011.

ECO, Umberto, MARTINI, Carlo Maria. Em que creem os que não creem?, Rio de Janeiro: Record. 2008.

HÄBERLE, Peter. México y los contornos de um derecho constitucional común americano: un ius commune americanum, in HÄBERLE, Peter, KOTZUR, Markus. De la soberania al derecho constitucional común: palabras clave para un diálogo europeu-latinoamericano, tradução de Héctor Fix-Fierro, Cuidad de México: Universidad Nacional Autónoma de México/Instituto de Investigaciones Jurídicas, 2003.

HABERMAS, Jürgen. Notas programáticas para a fundamentação de uma ética do discurso, in Consciência moral e agir comunicativo, tradução de Guido A. de Almeida, Rio de Janeiro: Tempo Brasileiro, 1989, pp. 61-142.

INGLEGART, Ronald, NORRIS, Pippa. Sacred and secular: religion and politics worldwide, 2 ed., Cambridge: Cambridge University Press, 2011.

KANT, Immanuel. Fundamentação à metafísica dos costumes, tradução de Paulo Quintela, Lisboa: Eduções 70, 2007.

KANT, Immanuel. Resposta à pergunta: o que é o iluminismo?, in A paz perpétua e outros opúsculos, tradução de Artur Morão, Lisboa: Edições 70, 1990.

LÓPEZ ARANGUREM, J. L. Ética y política, Madri: Morcelliana, 1966.

MEDEIROS, Alexandre. Jürgen Habermas y Paulo Freire: la democracia deliberativa y la pedagogía dialógica, in CAORSI, C, NAVIA, R. Actas del II Congresso Internacional de la Sociedad Filosófica de Uruguay, Montevideo: SFU, 2015, pp. 1214-1230.

MOUFFE, Chantal. On the political, Nova Iorque: Routledge, 2005.

ORGANIZAÇÃO DAS NAÇÕES UNIDAS. Programa das Nações Unidas para o Desenvolvimento. Relatório do Desenvolvimento Humano 2019, disponível em http://hdr.undp.org/sites/default/files/hdr_2019_overview_-_pt.pdf, acessado em 01.jul. 2019.

PEW RESEARCH CENTER. The Global God Divide: people's thoughts on whether elief in God is necessary to be moral vary by economic development, education and age. Disponível em https://www.pewresearch.org/global/2020/07/20/the-global-god-divide/, acessado em 21.jul. 2020.

PZREWORSKI, Adam. Crises of democracy, Cambridge: Cambridge University Press, 2019.

ROSENFELD, Michel. A identidade do sujeito constitucional e o estado democrático de direito, Cadernos da Escola do Legislativo, Belo Horizonte, v. 7, n. 12, jan/jun 2004.

ROSENFELD, Michel. A Identidade do Sujeito Constitucional, trd. Menelick de Carvalho Netto, Belo Horizonte: Melhoramentos, 2003.

SANTOS, Boaventura de Souza. Para Um Novo Senso Comum: A Ciência, o Direito e a Política na Transição Paradigmática, Vol. 1 (A Crítica da Razão Indolente: Contra o Desperdício da Experiência), 3 ed., São Paulo: Cortez, 2001.

SPINOZA, Benedictus de. Ética, tradução e notas Tomaz Tadeu, Belo Horizonte: Autêntica, 2008. 
TAYLOR, Charles. Política do reconhecimento, tradução de Deborah Christina Biet de Oliveira e Marcus Vinícius Xavier de Oliveira in DE OLIVEIRA, Marcus Vinícius Xavier, DANNER, Leno Francisco, CEI, Vitor et al (Orgs). Direitos humanos às beiras do abismo: Interlocuções entreDireito, Filosofia e Arte, Vila Velha: Praia Editora, 2018, pp. 34-82.

144 TRIBUNAL EUROPEU DE DIREITOS HUMANOS. Chamber Judgment. Case of Lautsi and Others v. Italy (application no. 30814/06), 2009.

TRIBUNAL EUROPEU DE DIREITOS HUMANOS. Grand Chamber. Case of Lautsi and Others v. Italy (application no. 30814/06), 2011.

VÁSQUEZ, Rodolfo. Entre la Libertad y la Igualdad. Introducción a la Filosofia del Derecho, Madri: Trotta, 2006.

1 Hannah empresa a expressão "hiato de credibilidade" que se tornou em um "abismo" às mentiras contidas nos famosos Documentos do Pentágono (HANNAH, 1999, p. 14).

2 Esse precedente foi objeto de overruling [procedimento do Common Law pelo qual há uma superação do precedente] pela Suprema Corte, em votação apertadíssima de 5 votos a favor e 4 contrários, no caso Obergefell vs. Hodges, de 2015, pelo qual a Corte considerou que a vedação de que pessoas do mesmo sexo contraíssem matrimônio violava às cláusulas do devido processo legal substantivo e da proteção igualitária pela lei, nos termos da XIV Emenda. É importante lembrar que muitas Supremas Cortes estaduais já vinham reconhecendo o direito à união homoafetiva em suas jurisdições estaduais.

3 "A frase de Goethe "natureza e arte parecem se evadir e se encontram da maneira mais inopinada", nos transmite uma tendência, mas não uma verdade última. Nos chamados países em desenvolvimento tem-se, todavia, consciência de seu significado como fator de identidade. Neste sentido há que se estabelecer, com toda a seriedade e não somente como exemplo humorístico, a pergunta de se os troncos de árvore, nos quais habitam os espíritos segundo os chamados "povos selvagens" da África, merecem proteção nacional e internacional como patrimônio cultural”. (HÄBERLE, 2003, p. 10).

4 Afirma-se atribuído porque a fonte indicada, a entrevista que Saramago deu a Ubiratan Brasil ao Jornal Estado de São Paulo em 17 de outubro de 2009 não consta nem a pergunta nem a resposta... ESTADO DE SÃO PAULO. "Deus não existe fora da cabeça das pessoas", disponível em https://cultura.estadao.com.br/noticias/geral,deus-nao-existe-fora-dacabeca-das-pessoas,452076, acessado 20.jul. 2020.

5 A referência ao princípio da universalidade pode ser compreendido a partir de duas acepções, uma estritamente jurídica, isto é, enquanto princípio jurídico fundamental do Direito Internacional dos Direitos Humanos que ilide, absolutamente, a exclusão de qualquer pessoa da esfera de proteção do direito, uma decorrência do direito à personalidade jurídica, e de outra perspectiva desde a concepção habermasiana contida no princípio U. Com efeito, Habermas, tomando por norte diferidor entre autonomia moral/razão prática e heteronomia/agir comunicativo, objetivando solvera controvérsia em torno do problema do solipsismo moral kantiano, propõe o conhecido Princípio U, segundo o qual "Todas as normas válidas tem que preencher a condição de que as consequências e efeitos colaterais que previsivelmente resultem de sua observância universal, para a satisfação dos interesses de todo indivíduo, possam ser aceitas sem coação por todos os interessados". Em outros termos, numa sociedade democrática, a condição de validade de uma decisão acerca da criação de uma regra não existe a priopri, uma vez que a ética do discurso se propõe, somente, a oferecer procedimentos racionais para a sua criação. (HABERMAS, 1989, pp. 61-142). 